\title{
Adaptive Fuzzy-PI Control for Active Front Steering System of Armoured Vehicles: Outer Loop Control Design for Firing On The Move System
}

\author{
Zulkiffli Abd Kadir*,1,2 - Saiful Amri Mazlan² - Hairi Zamzuri² - Khisbullah Hudha1 - Noor Hafizah Amer1 \\ 1National Defense University of Malaysia, Faculty of Engineering, Malaysia \\ 2Technology University of Malaysia, Malaysia-Japan International Institute of Technology, Malaysia
}

An armoured vehicle tends to lose its dynamic mobility when firing on the move. This is due to the effect of the firing force that reacts at the centre of the weapon platform, which creates an unwanted yaw moment at the vehicle's centre of gravity. In order to enhance the mobility performance of the armoured vehicle, a control strategy, i.e. yaw rejection control, is designed and test on an armoured vehicle model. The purpose of the control strategy is to maintain the directional mobility of the armoured vehicle by providing a steering correction angle to the pitman arm steering system. The control strategy proposed in this study consists of two main structures: yaw rate feedback control using a Proportional-Integral-Derivative (PID) controller and Lateral Force Rejection Control (LFRC) using an adaptive Fuzzy-Proportional-Integral (adaptive Fuzzy-PI) controller. The simulation results in terms of yaw and lateral motions were observed, and the proposed control strategy was shown to successfully improve the directional mobility of the armoured vehicle after firing. The benefit of the proposed control strategy with adaptive fuzzy-PI control is evaluated by comparing its performance to fuzzy-PI and proportional-integral (PI) control strategies.

Keywords: armoured vehicle model, validation of armoured vehicle model, active front steering, firing on the move, adaptive fuzzy control, lateral force control

Highlights
- The armoured vehicle model is developed.
- $\quad$ The armoured vehicle model was validated with a real armoured vehicle.
- The control strategy consists of adaptive fuzzy control with lateral force control.

\section{O INTRODUCTION}

An online controller is used to provide a stable condition for engineering systems due to the external disturbances and uncertain inputs by automatically changing the controller parameters to satisfy the necessity of system performance. Previous studies confirmed the advantages of fuzzy controller, which has intelligent functions that can be used to predict responses through a learning process, perform optimization work and is capable of maintaining the system performance due to changing condition [1]. However, there are several problems commonly associated with fuzzy controllers. First, it is always designed without obtaining the optimum range of the membership function inputs, value of outputs and controller rules. Without an optimum set of parameters, the performance of the controller and its ability to achieve a specific desired output will be compromised. The second common problem is developing the fuzzy controller on a nonlinear model without identifying the actual system parameters. In this case, a fuzzy controller will produce insignificant output performances. Hence, the control strategy using the existing fuzzy membership function will not be able to produce the optimum performance during the initial analysis work in order to achieve the required performance levels.

Based on the abovementioned problems, a method to automatically adjust the fuzzy controller parameters is required to overcome the effect of external disturbances while dealing with parameter optimizations and nonlinear system models. The parameters known as the centre and spread of the membership function for both inputs and output values were adjusted and optimized automatically to improve the controller performance. Fuzzy controllers with optimization capabilities are often called as "adaptive fuzzy". Currently, there are some research works that have proposed adaptive fuzzy controllers for nonlinear vehicle systems. Most of the adaptive fuzzy controllers were developed to meet the desired system performance, such as improving vehicle handling and ride stabilities performance using active suspension [2] and [3], controlling vehicle slip using antilock braking system [4], monitoring the vehicle gap keeping [5], developing electrical system for electric vehicle [6] and [7] and yaw moment control for independent rear wheel drives [8]. The primary intention of the proposed adaptive fuzzy controllers 
was to solve the problem of selecting the range of controller parameters that can deliver the desired system performance.

In this study, a control strategy of yaw rejection system for armoured vehicle using active front steering (AFS) system is proposed. The proposed control strategy for yaw rejection is developed on a validated four-wheeled armoured vehicle model. It consists of two outer loop controllers for yaw rate feedback and lateral force feedback. The aim of designing the outer loop controllers is to reduce the magnitude of unwanted motion in the lateral direction by minimizing yaw and lateral motions due to firing force. The outer loop controllers for yaw rate feedback and lateral force feedback proposed in this study have been developed using proportionalintegral-derivative (PID) control and fuzzy-PI control strategy, respectively. The proposed control strategy with adaptive fuzzy-proportional-integral (fuzzy-PI) control is then compared against the general fuzzyPI control and the conventional proportional-integral (PI) control to evaluate the effectiveness of adaptive fuzzy-PI control.

This paper is structured as follows: the introduction and previous works on adaptive fuzzy control are explained in the first section. The second section focuses on the mathematical equations of the armoured vehicle model and is followed by validation model in the third section. The next section shows the development of the proposed control strategy with adaptive Fuzzy-PI control. The sixth section discusses the simulation results of the adaptive Fuzzy-PI control and is followed by the overall conclusion in the last section.

\section{ARMOURED VEHICLE MODEL}

The armoured vehicle considered in this study, as illustrated in Fig. 1, is based on a category of a movable weapon system with four wheels and can fire a projectile from the gun turret.

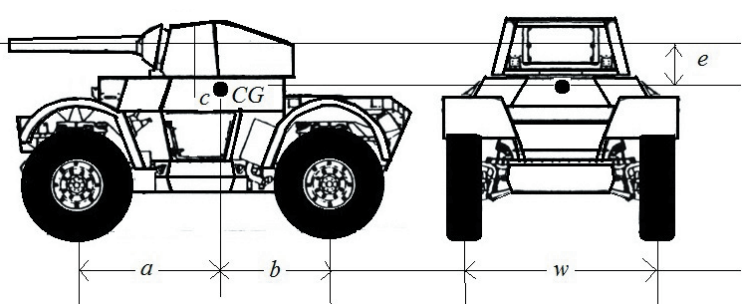

Fig. 1. A 2D view of four wheel armoured vehicle

The armoured vehicle covers the ride model and the handling model, which is free to pitch, roll and heave as well as allowing movements in longitudinal, lateral and yaw directions at its centre of gravity (CG).

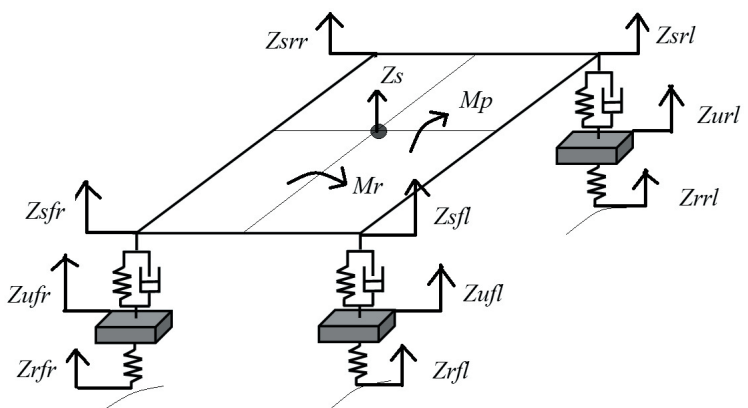

Fig. 2. Armoured vehicle ride model

Based on the armoured vehicle ride model shown in Fig. 2, the dynamics behaviour of the armoured vehicle in terms of pitch, roll, and heave motions are derived mathematically using equations of motions from Newton's second law as follows:

$$
\begin{aligned}
I_{p} \ddot{\theta} & =\left(F_{s r l}+F_{d r l}+F_{s r r}+F_{d r r}\right) b- \\
& -\left(F_{s f l}+F_{d f l}+F_{s f r}+F_{d f r}\right) a+m_{s} a_{x} h_{c G},
\end{aligned}
$$

$$
\begin{aligned}
I_{r} \ddot{\varphi} & =\left(F_{s f r}+F_{s r r}+F_{d f r}+F_{d r r}\right) \frac{w}{2}- \\
& -\left(F_{s f l}+F_{s r l}+F_{d f l}+F_{d r l}\right) \frac{w}{2}+m_{s} a_{y} h_{C G},
\end{aligned}
$$

$m_{s} \ddot{Z}_{s}=F_{s f l}+F_{d f l}+F_{s f r}+F_{d f r}+F_{s r l}+F_{d r l}+F_{s r r}+F_{d r r}$

where $\ddot{\varphi}$ is the angular acceleration of roll at body $C G\left[\mathrm{rad} / \mathrm{s}^{2}\right], I_{r}$ is the moment inertia of roll axis $\left[\mathrm{kg} / \mathrm{m}^{2}\right], h_{C G}$ is the distance between roll axis and $C G[\mathrm{~m}], w$ is the vehicle track width [m], $a_{y}$ is lateral acceleration $\left[\mathrm{m} / \mathrm{s}^{2}\right], \ddot{\theta}$ is the angular acceleration of pitch at body $C G\left[\mathrm{rad} / \mathrm{s}^{2}\right], I_{p}$ is the moment inertia of pitch axis $\left[\mathrm{kg} / \mathrm{m}^{2}\right], a$ is distance from the front tyre to the body $C G[\mathrm{~m}], b$ is distance from the rear tyre to the body $C G[\mathrm{~m}], a_{x}$ is longitudinal acceleration $\left[\mathrm{m} / \mathrm{s}^{2}\right], m_{s}$ is the armoured vehicle's mass $[\mathrm{kg}], \ddot{Z}_{s}$ is the vertical acceleration of sprung mass at $C G\left[\mathrm{~m} / \mathrm{s}^{2}\right]$, $F_{s i j}$ is suspension force $[\mathrm{N}]$ and $F_{d i j}$ is damper force [N].

Fig. 3 illustrates the armoured vehicle handling model. The longitudinal and lateral accelerations can be obtained by considering the forces acting on each tyre in the longitudinal direction, $x$-axis and longitudinal direction, $y$-axis as follows:

$$
\begin{gathered}
F_{x r r}+F_{x r l}-F_{y f r} \sin \delta+F_{x f r} \cos \delta- \\
-F_{y f l} \sin \delta+F_{x f l} \cos \delta-F_{e} \cos \beta=m_{s} a_{x},
\end{gathered}
$$




$$
\begin{gathered}
F_{y r r}+F_{y r l}+F_{x f r} \sin \delta+F_{y f r} \cos \delta+ \\
+F_{x f l} \sin \delta+F_{y f l} \cos \delta+F_{e} \sin \beta=m_{s} a_{y},
\end{gathered}
$$

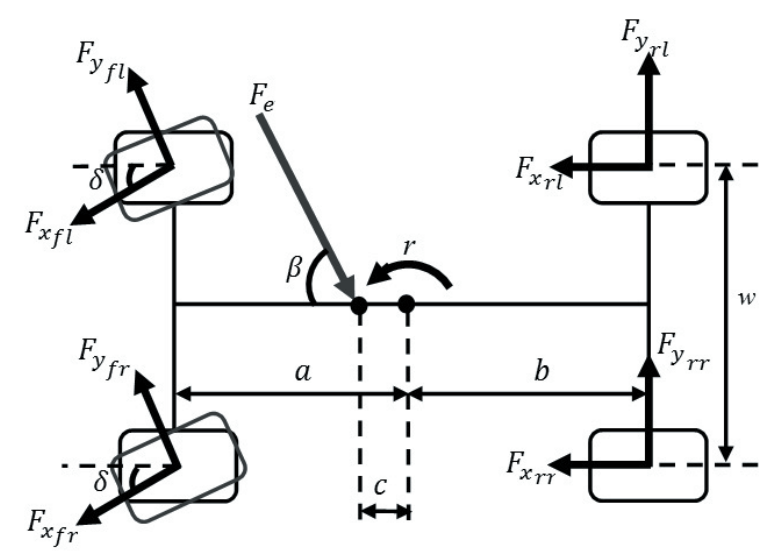

Fig. 3. Armoured vehicle handling model with firing disturbance

The yaw angular acceleration acting on the armoured vehicle handling model is also based on the effects of tyre forces, i.e. lateral force and longitudinal force, and it can be derived as:

$$
\left(\begin{array}{l}
-\frac{w}{2} F_{x f r} \cos { }^{\prime}+\frac{w}{2} F_{x f l} \cos \delta-\frac{w}{2} F_{x r r}+ \\
+\frac{w}{2} F_{x r l}+\frac{w}{2} F_{y f l} \sin ^{\prime}-\frac{w}{2} F_{y f r} \sin ^{\prime}- \\
-b F_{y r l}-b F_{y r r}+a F_{y f l} \cos ^{\prime}+a F_{y f r} \cos ^{\prime}- \\
-a F_{x f l} \sin ^{\prime}-a F_{x f r} \sin ^{\prime}+c F_{e} \sin \beta
\end{array}\right)=I_{z} \ddot{r},(6)
$$

where $I_{z}$ is the moment of inertia around $z$-axis $\left[\mathrm{kg} / \mathrm{m}^{2}\right], \delta$ is the tyre steer angle [rad], $\ddot{r}$ is yaw angular acceleration $\left[\mathrm{rad} / \mathrm{s}^{2}\right]$ and $m_{s}$ is the armoured vehicle's mass $[\mathrm{kg}]$.

\section{VALIDATION OF ARMOURED VEHICLE MODEL}

In order to validate the armoured vehicle model, a handling test was conducted using a Ferret Scout Car armoured vehicle. Several transducers were installed in the armoured vehicle to observe the vehicle's behaviour such as lateral acceleration, roll angle, yaw rate and steering input from the driver, as shown in Fig. 4. Validation of the developed armoured vehicle model can be defined as an assessment and comparison of the developed model's behaviours with the actual armoured vehicle's behaviours [9]. The validation of the armoured vehicle model is done by comparing the behaviour obtained from the simulation model with the actual responses obtained from the experimental armoured vehicle using similar handling test. The experimental results were also used to optimize the parameters of the developed armoured vehicle model.

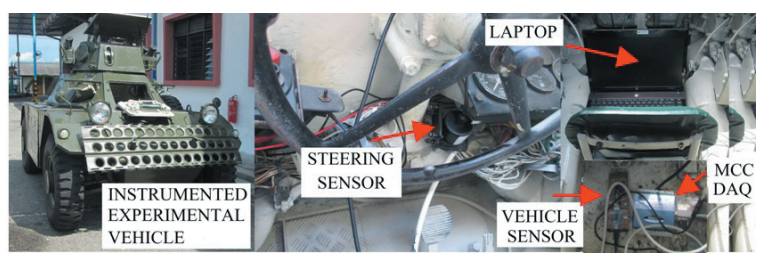

Fig. 4. Instrumented experimental armored vehicle

The model validation is performed for a double lane change test. However, due to several constraints, such as limitation of the experimental area and the speed of the Ferret Scout Car, the experimental work is performed with speed of $40 \mathrm{~km} / \mathrm{h}$. Fig. 5 shows the steering input delivered by the driver in double lane change test.

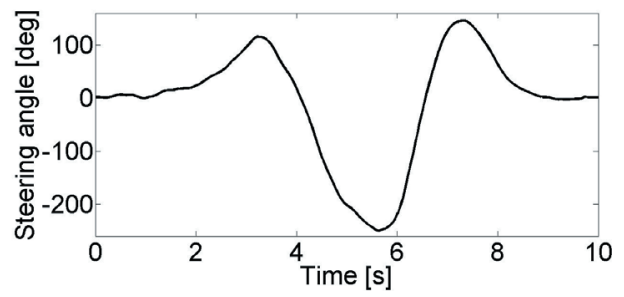

Fig. 5. Steering wheel angle

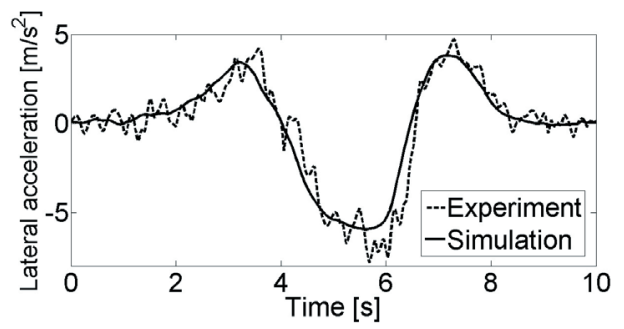

Fig. 6. Lateral acceleration response

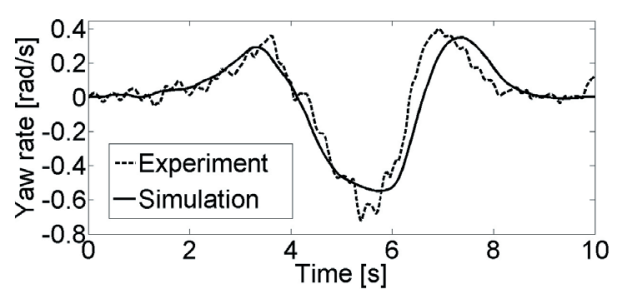

Fig. 7. Yaw rate response

The validation results for the double lane change test are analysed in terms of lateral acceleration, yaw rate and roll angle of the armoured vehicle. The results are shown in Fig. 6 to 8, respectively. It can be seen that simulation model has similar trends and magnitudes with the actual manoeuvring of the armoured vehicle. The small deviations in the 
validation results were caused by the error from the driver in maintaining a constant speed for the actual handling test. For the overall validation results, it is clear that the behaviours obtained from the simulation work and the experimental work for the double lane change test have similar responses with acceptable rates of error. The validated armoured vehicle model is then used to develop a yaw cancellation system using active front steering in the next section.

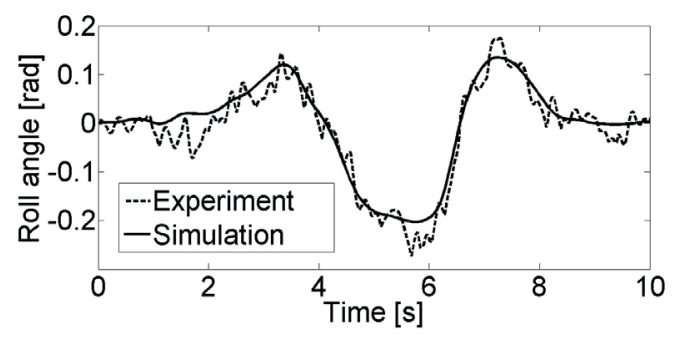

Fig. 8. Roll angle response

\section{THE PROPOSED CONTROL STRATEGY OF AFS FOR ARMOURED VEHICLES}

The AFS for four-wheeled armoured vehicles is developed by installing an additional mechanism consisting of a direct current (DC) motor, known as an AFS actuator as well as AFS gearbox, as illustrated in Fig. 9.

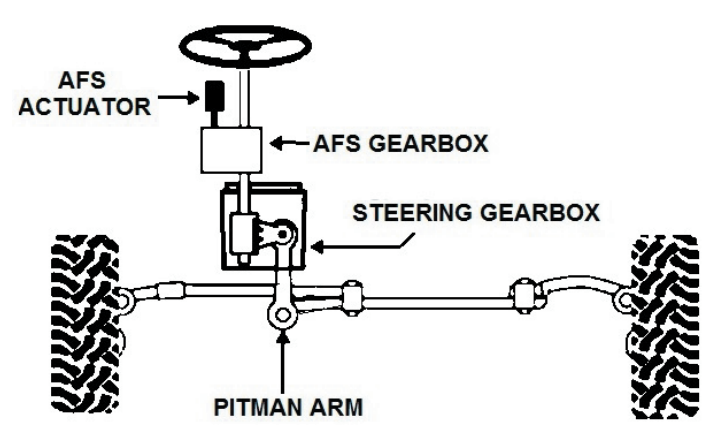

Fig. 9. Configuration of active front steering using pitman steering

This mechanism is installed in the conventional Pitman arm steering system by maintaining the existing parts, including the steering wheel, steering column, recirculating ball gearbox, pitman arm and steering linkage. The AFS gearbox is used to superimpose the steering wheel angle obtained from the driver and angle of steering correction from the AFS actuator. In AFS, there are two angles need to be evaluated: the steering wheel input given by the driver and the steering correction angle generated by the AFS actuator. The combination of both angles provides a correction angle to the front wheels through the Pitman arm joint.

In this study, an additional controller loop is introduced as lateral force rejection control (LFRC). The purposed of LFRC loop is used to measure the estimated lateral force $\left(F_{y e}\right)$ in order to eliminate the unwanted lateral motion due to the firing impact. The LFRC is adopted from the principle of skyhook control usually used in suspension control, the main purpose of which is to improve the vertical behaviour of the vehicle subjected to road disturbances [10] and [11]. Using the same concept, skyhook control principle was applied in LFRC to reduce unwanted disturbances in lateral direction. The configuration of the estimated lateral force is shown in Fig. 10, which consists of an imaginary lateral damper $\left(C_{\text {lateral }}\right)$ to provide virtual damping for the system and an imaginary lateral wall as the reference point.

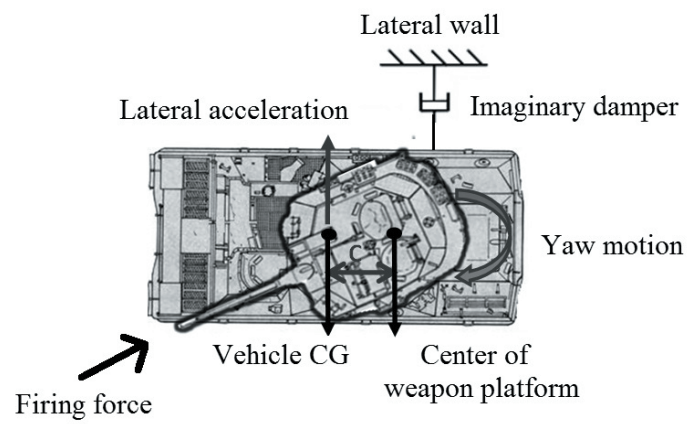

Fig. 10. Armored vehicle with imaginary lateral wall and imaginary lateral damper

The estimated lateral force $\left(F_{y e}\right)$ is defined as:

$$
F_{y e}=C_{\text {lateral }} \dot{y}_{G C} .
$$

Here, $\dot{y}_{G C}$ is known as the lateral velocity of the armoured vehicle. This can be obtained by differentiating the global coordinate of lateral displacement $\left(y_{G C}\right)$ of the armoured vehicle. The lateral displacement of $y_{G C}$ is defined as:

$$
y_{G C}=y_{o}+\int v_{y} \cos r+v_{x} \sin r
$$

where $y_{o}$ is the local lateral displacement [m], $r$ is the armoured vehicle's yaw angle [rad], $v_{x}$ the armoured vehicle's longitudinal velocity $[\mathrm{m} / \mathrm{s}]$, and $v_{y}$ the armoured vehicle's lateral velocity $[\mathrm{m} / \mathrm{s}]$.

The proposed AFS control strategy is designed using a four-wheel armoured vehicle model as shown in Fig. 11. The system is developed by assuming that the armoured vehicle travels in the longitudinal direction without any steering input from the driver. 


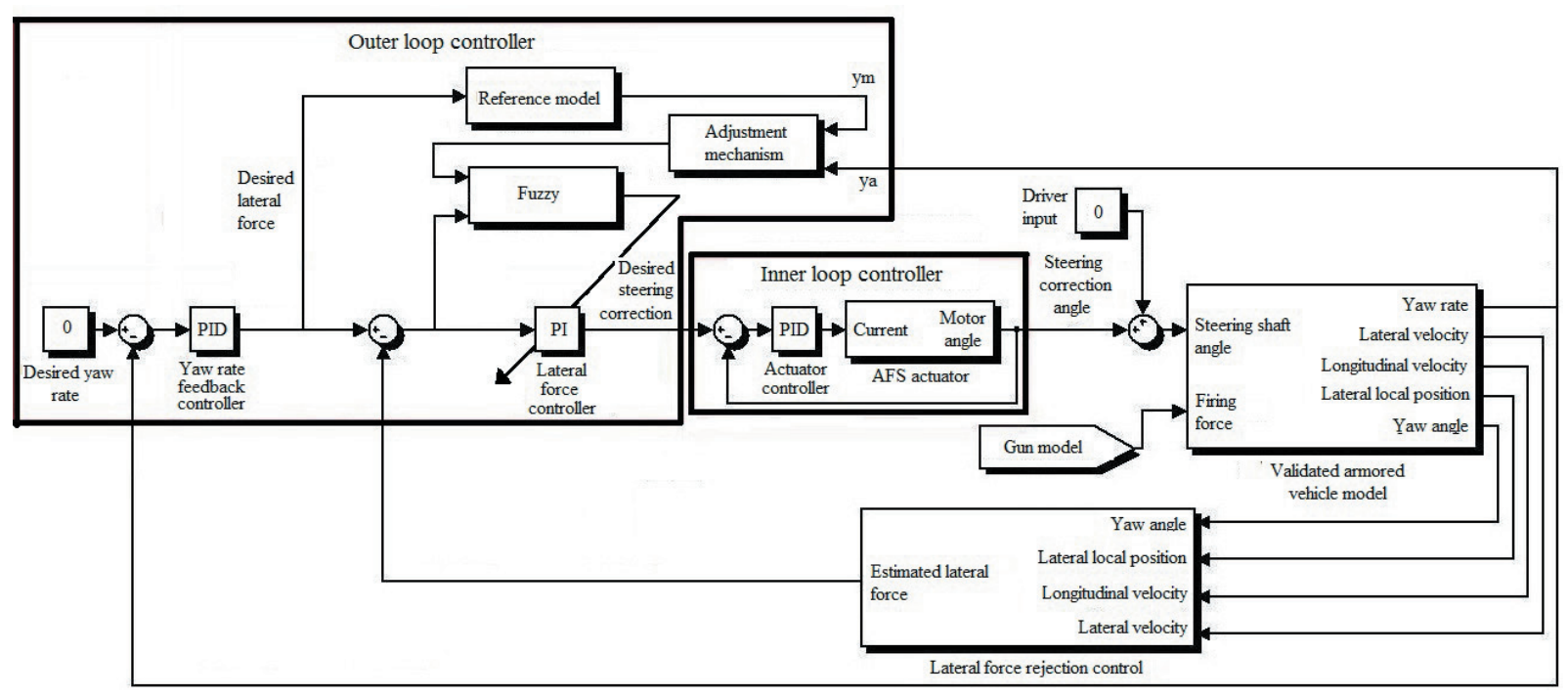

Fig. 11. Control strategy of AFS for armored vehicle

This control strategy consists of two feedback loop controllers, which are inner and outer loop controls. The inner loop controller is developed to control the AFS actuator while the outer loop controller is to control the overall dynamic performance of the armoured vehicle during firing. In the outer loop controller, both the yaw rate and lateral force controller feedback are used to reject the unwanted yaw motion while simultaneously minimizing the lateral movement of the armoured vehicle subjected to firing impact.

A conventional PID controller is used as the yaw rate feedback controller in order to estimate the yaw rate error of the armoured vehicle. This error is used as the reference point for the following controller loop, known as the lateral force control. This lateral force control is monitored by a self-tuning PI control adapted by a nonlinear fuzzy membership function. Henceforth, the desired lateral force $\left(F_{y d}\right)$ is defined as:

$$
F_{y d}=\left(K_{p y}+\frac{K_{i y}}{s}+K_{d y} s\right)\left(y_{d}-y_{a}\right)
$$

where $y_{a}$ is actual yaw rate, $y_{d}$ is desired yaw rate, while $K_{p y}, K_{i y} / S$ and $K_{d y} s$ are vehicle controllers for yaw rate response. $F_{y d}$ is compared with the estimated lateral force $\left(F_{y e}\right)$ in order to measure the desired angle of steering correction $\left(\delta_{d}\right)$. The steering correction is used to counterback the steering wheel angle due to the firing disturbance acting at the centre of weapon platform. Therefore, the $\delta_{d}$ is measured as below:

$$
\delta_{d}=\left(K_{p l}+\frac{K_{i l}}{s}\right)\left(F_{y d}-F_{y e}\right),
$$

where $K_{p l}$ and $K_{i l} / S$ are proportional and integral gains for lateral force control, respectively. Initially, the gain values of proportional and integral are set to be a constant values throughout the simulation procedure. However, these constant values are not compatible once the conditions or disturbances vary with time. Hence, a self-tuning method is required in order to tune the constant values according to the disturbance or condition. The self-tuning method can be implemented for both proportional and integral gains by identifying the maximum and minimum gain values through the simulation procedure. The range of the proportional and integral gains are $K_{p l} \in[1.5,0.1]$ and $K_{i l} \in[0.08,0.01]$. The range of each gains can be used to calibrate $K_{p l}^{\prime}$ and $K_{i l}^{\prime}$ as follows:

$$
\begin{gathered}
K_{p l}^{\prime}=\frac{K_{p l}-K_{p l \min }}{K_{p l \text { max }}-K_{p l \min }}=\frac{K_{p l}-0.1}{1.5-0.1}, \\
K_{i l}^{\prime}=\frac{K_{i l}-K_{i l \min }}{K_{i l \text { max }}-K_{i l \text { min }}}=\frac{K_{i l}-0.01}{0.08-0.01},
\end{gathered}
$$

where $K_{p l}^{\prime}$ and $K_{i l}^{\prime}$ are the update values for $K_{p l}$ and $K_{i l}$. Both equations can be rearranged as $K_{p l}=1.4 K_{p l}^{\prime}+0.1$ and $K_{i l}=0.07 K_{i l}^{\prime}+0.01$. Although the self-tuning PI control is used in this control strategy, the performance of the armoured vehicle due to firing needs more improvement in term of lateral displacement and the stability of the armoured 
vehicle. Hence, a nonlinear fuzzy control is merged with a self-tuning PI controller. The combination of a self-tuning Fuzzy-PI controller is used to increase the dynamic performance of the armoured vehicle during firing. The equations of the nonlinear fuzzy control are described as follows:

$$
y_{p}=f(x \mid \theta)=\frac{\sum_{i=1}^{r} b_{i} \Pi_{j=1}^{n} \exp \left(-\frac{1}{2}\left(\frac{x_{j}-c_{j}^{i}}{\sigma_{j}^{i}}\right)^{2}\right)}{\sum_{i=1}^{r} \Pi_{j=1}^{n} \exp \left(-\frac{1}{2}\left(\frac{x_{j}-c_{j}^{i}}{\sigma_{j}^{i}}\right)^{2}\right)},
$$

where, $x_{j}$ is input to the fuzzy set, $j=1, \ldots, n$ ( $n$ is number of inputs) and $i=1, \ldots, r$ ( $r$ is the number of rules). The parameter $b_{i}$ is the output values of the fuzzy set, while $c_{j}^{i}$ and $\sigma_{j}^{i}$ are centre and spread of Gaussian membership function inputs, respectively. However, the parameters of the fuzzy control itself need to be configured varying with time since there are several constant parameters which are $b, c$ and $\sigma$. Therefore, an adaption law is absorbed in the self-tuning Fuzzy-PI controller in order to enhance the performance of the AFS control strategy. The adaptation law is developed based on an adjustment mechanism to update the constant parameters of the fuzzy controller. The adjustment mechanism for the fuzzy controller is developed using first order reference model as shown in Fig. 11. The intention of the adjustment mechanism is to vary the fuzzy controller parameters, i.e. $b, c$ and $\sigma$. The yaw rate $\left(y_{a}\right)$ response is considered in designing the adjustment mechanism of the fuzzy control. It is assumed that output from fuzzy control $f(x \mid \theta)$ is similar with the yaw rate response, and error $\left(e_{m}\right)$ for the adjustment mechanism can be written as:

$$
e_{m}=\frac{1}{2}\left(y_{a}-y_{m}\right)^{2}=\frac{1}{2}\left(f(x \mid \theta)-y_{m}\right)^{2},
$$

$e_{m}$ is designed to minimize error between the reference model $\left(y_{m}\right)$ and yaw rate response $\left(y_{a}\right)$. By considering the number of rules $(r)$, the parameters of input $c$, $\sigma$ and the output parameter $b$ can be adjusted by updating the parameter values using gradient descent method as follows:

$$
\begin{aligned}
& b_{i}(k+1)=b_{i}(k)-\lambda_{1} \frac{\partial e_{m}}{\partial b_{i}}, \\
& c_{i}(k+1)=c_{i}(k)-\lambda_{2} \frac{\partial e_{m}}{\partial c_{i}},
\end{aligned}
$$

$$
\sigma_{i}(k+1)=\sigma_{i}(k)-\lambda_{3} \frac{\partial e_{m}}{\partial \sigma_{i}}
$$

where, update parameter values $\lambda_{1}, \lambda_{2}$ and $\lambda_{3}$ need to be fine tuned. The first derivative of adjustment error $\left(e_{m}\right)$ with respect to fuzzy parameters $b, c$ and $\sigma$ are written as follows:

$$
\begin{gathered}
b_{i}(k+1)=b_{i}(k)-\lambda_{1}\left(f(x \mid \theta)-y_{m}\right) \frac{z^{i}}{w}, \\
c_{i}(k+1)=c_{i}(k)-\lambda_{2}\left[f(x \mid \theta)-y_{m}\right]\left[b_{i}(k)-\right. \\
\left.-f\left(x^{m} \mid \theta(k)\right)\right]\left[\frac{x_{j}^{m}-c_{j}^{i}(k)}{\left(\sigma_{j}^{i}(k)\right)^{2}}\right] \frac{z^{i}}{w}, \\
\sigma_{i}(k+1)=\sigma_{i}(k)-\lambda_{3}\left[f(x \mid \theta)-y_{m}\right]\left[b_{i}(k)-\right. \\
\left.-f\left(x^{m} \mid \theta(k)\right)\right]\left[\frac{\left(x_{j}^{m}-c_{j}^{i}(k)\right)^{2}}{\left(\sigma_{j}^{i}(k)\right)^{3}}\right] \frac{z^{i}}{w},
\end{gathered}
$$

where,

$$
z^{i}=\prod_{j=1}^{n} \exp \left(-\frac{1}{2}\left(\frac{x_{j}^{m}-c_{j}^{i}}{\sigma_{j}^{i}}\right)^{2}\right),
$$

and

$$
w=\sum_{i=1}^{r} z^{i}
$$

\section{PERFORMANCE ASSESSMENT OF THE ADAPTIVE FUZZY-PI CONTROL FOR ARMOURED VEHICLE USING ACTIVE FRONT STEERING}

The performance of proposed control strategy is analysed for a duration of 2.5 seconds. The control parameters of PI control, parameters of the armoured vehicle model, membership functions of Fuzzy-PI, input rules of Fuzzy-PI control output rules of fuzzyPI control and control parameters of adaptive fuzzy-PI control are presented in Tables 1 and 2, Fig. 12 and Tables 3 to 5 , respectively.

Table 1. Controller parameters for control strategy with PI control

\begin{tabular}{lccc}
\hline Yaw Rate Controller & $K_{p y}=40$ & $K_{i y}=4$ & $K_{d y}=3$ \\
\hline Lateral Force Controller & $K_{p l}=1.5$ & $K_{i l}=0.08$ & - \\
\hline
\end{tabular}

The cumulative Gaussian for error and error rate membership functions are set as negative big (NB), negative small (NS), zero (ZE), positive small (PS) and positive big (PB). Meanwhile, the output values 
to update the PI control are set as big (B), medium big (MB), medium (M), medium small (MS) and small (S).

Table 2. Armoured vehicle model parameters

\begin{tabular}{lc}
\hline Armoured vehicle mass, $m_{S}[\mathrm{~kg}]$ & 4000 \\
\hline Distance front tyre to the body CG, $a[\mathrm{~m}]$ & 1 \\
\hline Distance rear tyre to the body CG, $b[\mathrm{~m}]$ & 1.3 \\
\hline Distance from roll axis to CG, $h_{C G}[\mathrm{~m}]$ & 0.5 \\
\hline Moment of inertia around $z$-axis, $I_{z}\left[\mathrm{~kg} / \mathrm{m}^{2}\right]$ & 5000 \\
\hline Moment inertia of roll axis, $I_{r}\left[\mathrm{~kg} / \mathrm{m}^{2}\right]$ & 500 \\
\hline Damping stiffness at front left, front right, rear left, & 10000 \\
rear right, $K_{s f l}, K_{s f r}, K_{s r l}, K_{s r r}[\mathrm{~N} / \mathrm{m}]$ & \\
\hline $\begin{array}{l}\text { Damping stiffness at front left, front right, rear left, } \\
\text { rear right, } C_{s f l}, C_{s f r}, C_{s r l}, C_{s r r}\left[\mathrm{~N} / \mathrm{ms}^{-1}\right]\end{array}$ & 800 \\
\hline Track width, $w[\mathrm{~m}]$ & 1.5 \\
\hline
\end{tabular}

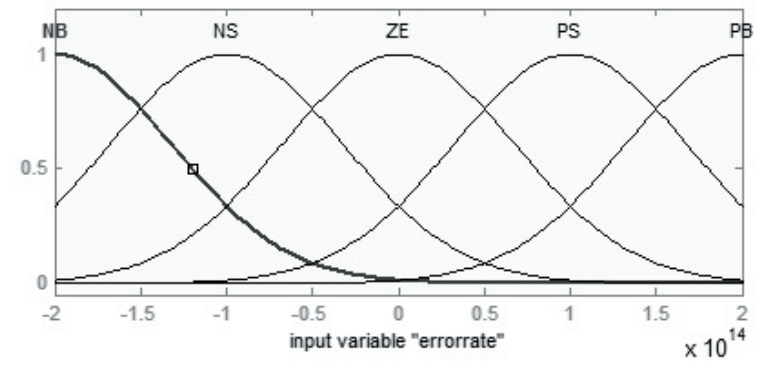

a) Error membership function

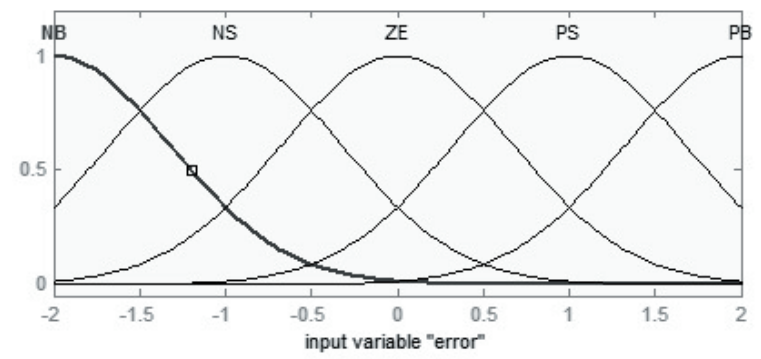

b) Error rate membership function

Fig. 12. Membership functions of Fuzzy-PI control for error rate and error

Table 3. Fuzzy rules for control strategy with Fuzzy-PI control

\begin{tabular}{cccccc}
\hline Error Rate/Error & $\mathrm{NB}$ & $\mathrm{NS}$ & $\mathrm{ZE}$ & $\mathrm{PS}$ & $\mathrm{PB}$ \\
\hline $\mathrm{NB}$ & $\mathrm{S}$ & $\mathrm{S}$ & $\mathrm{MS}$ & $\mathrm{MS}$ & $\mathrm{M}$ \\
\hline $\mathrm{NS}$ & $\mathrm{S}$ & $\mathrm{MS}$ & $\mathrm{MS}$ & $\mathrm{M}$ & $\mathrm{MB}$ \\
\hline $\mathrm{ZE}$ & $\mathrm{MS}$ & $\mathrm{MS}$ & $\mathrm{M}$ & $\mathrm{MB}$ & $\mathrm{MB}$ \\
\hline $\mathrm{PS}$ & $\mathrm{MS}$ & $\mathrm{M}$ & $\mathrm{MB}$ & $\mathrm{MB}$ & $\mathrm{B}$ \\
\hline $\mathrm{PB}$ & $\mathrm{M}$ & $\mathrm{MB}$ & $\mathrm{MB}$ & $\mathrm{B}$ & $\mathrm{B}$ \\
\hline
\end{tabular}

Table 4. Fuzzy output values for control strategy with Fuzzy-PI control

\begin{tabular}{cccccc}
\hline Update value for PI control & $\mathrm{S}$ & $\mathrm{MS}$ & $\mathrm{M}$ & $\mathrm{MB}$ & $\mathrm{B}$ \\
\hline$K_{p l}^{\prime}$ & 0.1 & 0.75 & 1.5 & 2.25 & 3 \\
\hline$K_{i l}^{\prime}$ & 0.01 & 0.04 & 0.08 & 0.12 & 0.16 \\
\hline
\end{tabular}

Table 5. Controller parameters for control strategy with adaptive Fuzzy-PI control

\begin{tabular}{cc}
\hline Update parameter & Value \\
\hline$\lambda_{1}$ & -30 \\
\hline$\lambda_{2}$ & 4000 \\
\hline$\lambda_{3}$ & 10000 \\
\hline
\end{tabular}

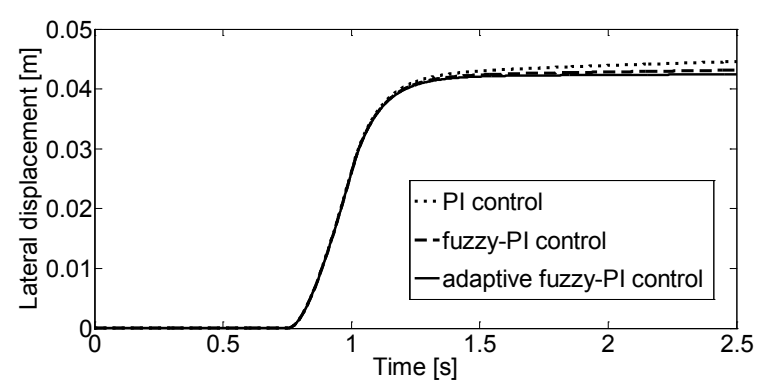

a) Firing angle of 30 degrees

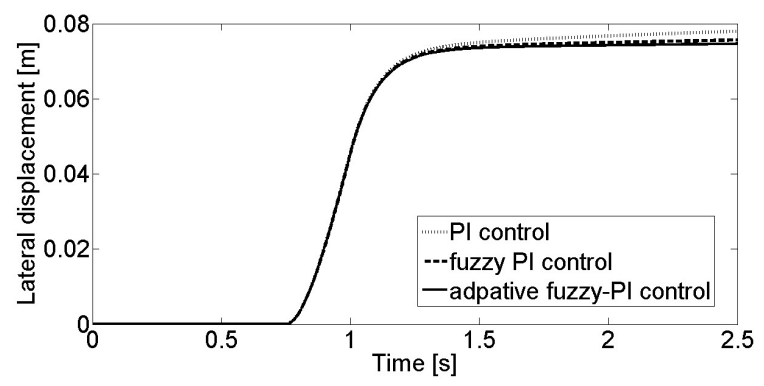

b) Firing angle of 60 degrees

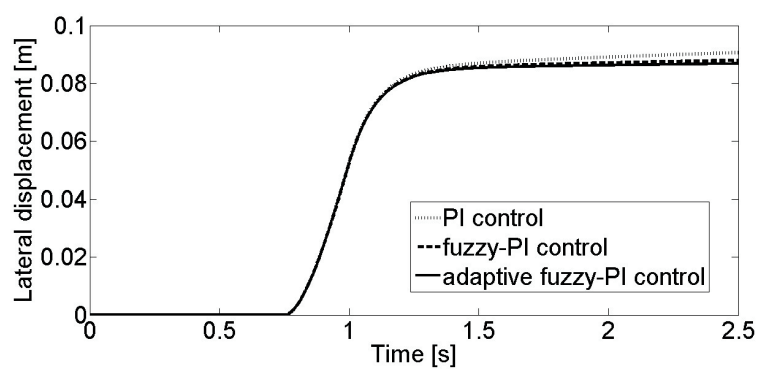

c) Firing angle of 90 degrees

Fig. 13. Lateral displacement responses for various firing angles

Simulation results of armoured vehicle body displacement in lateral motion are shown in Fig. 13. The firing angles of the armoured vehicle are set at 30, 60 and 90 degrees with a constant cruising speed of $40 \mathrm{~km} / \mathrm{h}$. The effectiveness of the adaptive Fuzzy- 
PI control strategy can be evaluated from the lateral displacement error of the armoured vehicle after the firing condition. The control strategy with adaptive Fuzzy-PI control managed to reduce the magnitude of lateral displacement error and maintain the direction of travel after firing, in comparison to its counterparts, i.e. Fuzzy-PI and PI controls. The controller's ability to improve the dynamics performance in lateral direction will ensure better mobility for the armoured vehicle when firing on the move.

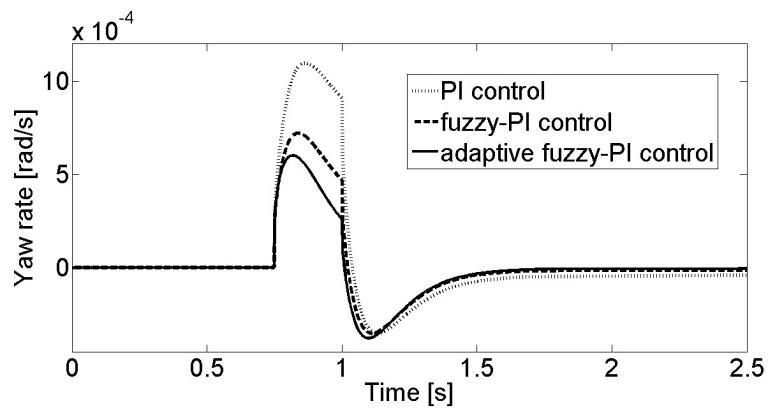

a) Firing angle of 30 degrees

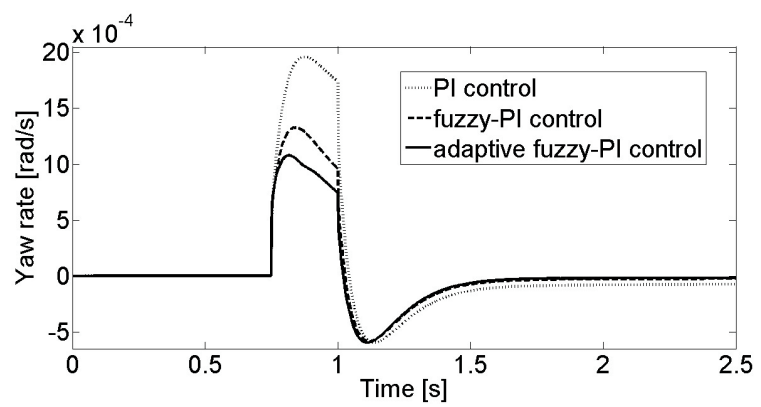

b) Firing angle of 60 degrees

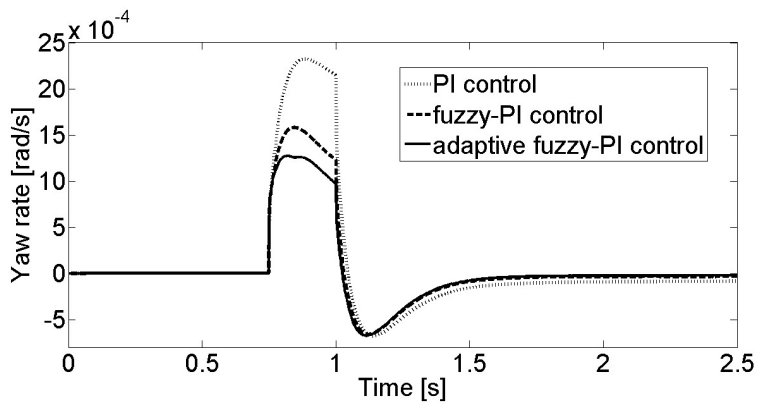

c) Firing angle of 90 degrees

Fig. 14. Yaw rate responses for various firing angles

Similar performance also can be observed in the yaw rate and yaw angle, as shown in Figs. 14 and 15 , respectively. In both cases, the control strategy with the adaptive Fuzzy-PI control shows better performance in minimizing both the settling time and the response magnitude in comparison to the control strategy with Fuzzy-PI and PI controls. For the yaw rate response in Fig. 14, it can be observed that the control strategy with adaptive Fuzzy-PI control has been successful in minimizing the yaw rate magnitude as compared to its counterparts. The control strategy with the adaptive Fuzzy-PI control also managed to isolate armoured vehicle body from the unwanted yaw rate almost $20 \%$ more than the Fuzzy-PI control for all firing angles. By isolating the unwanted yaw rate from the armoured vehicle body, the dynamics stability of the armoured vehicle during firing on the move can be improved. This will improve the vehicle's ability to move at the intended direction when firing. Furthermore, the probability of the armoured vehicle becoming unstable can be minimized.

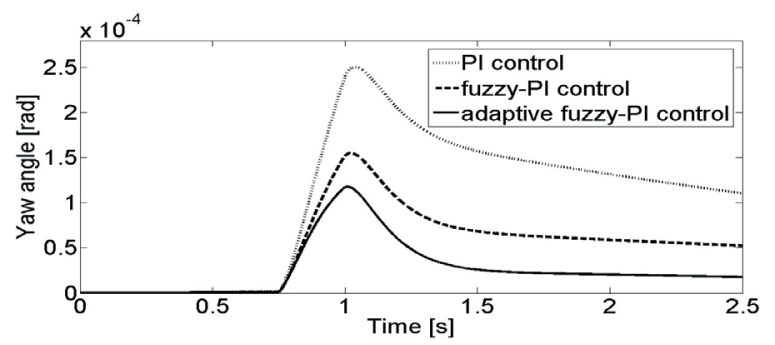

a) Firing angle of 30 degrees

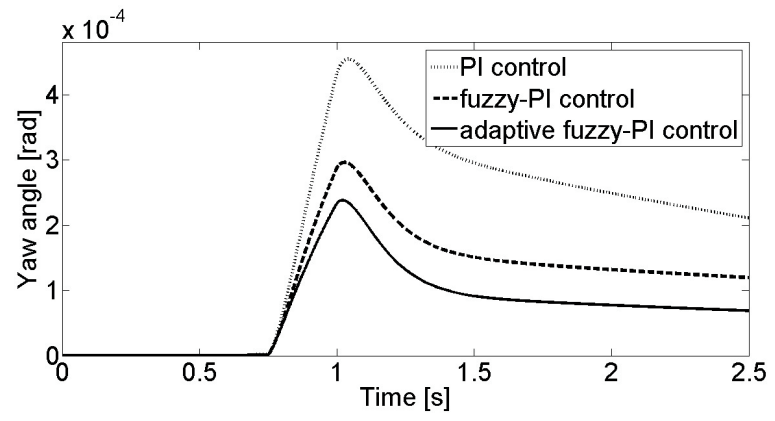

b) Firing angle of 60 degrees

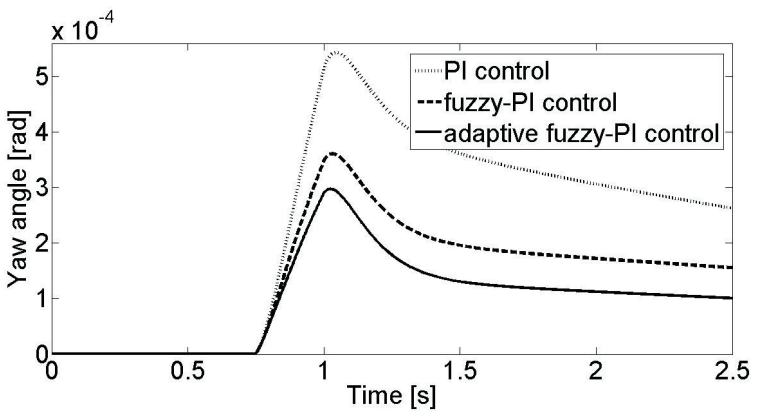

c) Firing angle of 90 degrees

Fig. 15. Yaw angle responses for various firing angles

Similarly, the control strategy with the adaptive Fuzzy-PI control demonstrates a significant reduction on yaw angle response at body centre of gravity on firing test with angles of 30,60 and 90 degrees 
compared to Fuzzy-PI and PI controls, as shown in Fig. 15. From the simulation results, it is evident that the adaptive Fuzzy-PI control is very effective in minimizing the yaw angle error. The yaw angle response for all firing tests is summarized in Table 6. By minimizing the yaw angle error, directional stability of armoured vehicle during firing while moving can be improved, which is the major aspect of armoured vehicle safety.

Table 6. Yaw angle responses for firing angle of 30, 60 and 90 degrees

\begin{tabular}{cccc}
\hline \multirow{2}{*}{$\begin{array}{c}\text { Firing } \\
\text { angle }\left[{ }^{\circ}\right]\end{array}$} & \multicolumn{3}{c}{ Yaw angle response } \\
\cline { 2 - 4 } & $\mathrm{PI}$ [rad] & Fuzzy-PI [rad] & Adaptive fuzzy-PI [rad] \\
\hline 30 & $2.5 \times 10^{-4}$ & $1.5 \times 10^{-4}$ & $1.1 \times 10^{-4}$ \\
\hline 60 & $4.6 \times 10^{-4}$ & $2.9 \times 10^{-4}$ & $2.2 \times 10^{-4}$ \\
\hline 90 & $5.4 \times 10^{-4}$ & $3.6 \times 10^{-4}$ & $2.9 \times 10^{-4}$ \\
\hline
\end{tabular}

\section{CONCLUSION}

A control strategy for an armoured vehicle using AFS system has been developed on a validated model of a four-wheel armoured vehicle using MATLAB-SIMULINK. The main purpose of this proposed control strategy is to enhance the dynamic performance of the armoured vehicle, such as lateral displacement, yaw rate and yaw angle when firing on the move. There are two feedback controllers used in this study: yaw rate feedback using PID control and lateral force feedback using adaptive Fuzzy-PI control. The proposed AFS control strategy is then evaluated via simulation involving various firing angles of 30 , 60 and 90 degrees. Based on the simulation results, it can be observed that the proposed AFS control strategy using the adaptive Fuzzy-PI controller performed significantly better in comparison to the Fuzzy-PI and conventional PI control strategy. This improvement of the armoured vehicle due to lateral and yaw performances can increase the stability of the armoured vehicle after the firing impact. Furthermore, the soldiers driving the armoured vehicle are able to control the vehicle even after the firing impact from the gun.

\section{ACKNOWLEDGMENT}

The authors would like to thank the Malaysian Ministry of Education through RAGS (RAGS/2012/ UPNM/TK01/4), LRGS (LRGS/B-U/2013/UPNM/ DEFENCE \& SECURITY-P1), Institut Kejuruteraan Tentera Darat (IJED) and the Malaysia-Japan
International Institute of Technology (MJIIT) for their financial support and the use of their research facility for this research.

\section{REFERENCES}

[1] Sa-ngawong, N., Ngamroo, I. (2015). Intelligent photovoltaic farms for robust frequency stabilization in multi-area interconnected power system based on PSO-based optimal Sugeno fuzzy logic control. Renewable Energy, vol. 74, p. 555567, D0I:10.1016/j.renene.2014.08.057.

[2] Chiou J.S., Tsai, S.H., Liu, M.T. (2012). A PSO-based adaptive fuzzy PID-controllers. Simulation Modelling Practice and Theory, vol. 26, p. 49-59, D0l:10.1016/j.simpat. 2012.04.001.

[3] Mailah, M., Priyandoko, G. (2007). Simulation of a suspension system with adaptive fuzzy active force control. International Journal of Simulation Modelling, vol. 6, no. 1, p. 25-36, DOI:10.2507/IJSIMM06(1)3.079.

[4] Wang, W.Y., Li, I.H., Tsai, C.P., Su, S.F., Hsu, S.B. (2009). Dynamic Slip-Ratio Estimation and Control of Antilock Braking Systems Using an Observer-Based Direct Adaptive FuzzyNeural Controller. IEEE Transactions on Industrial Electronics, vol. 56, no. 5, p. 1746-1756, DOl:10.1109/TIE.2008.2009439.

[5] Naranjo, J.E., Gonzalez, C., Reviejo, J., Garcia, R., de Pedro, T. (2003). Systems adaptive fuzzy control for inter-vehicle gap keeping. IEEE Transactions on Intelligent Transportation Systems, vol. 4, no. 3, p. 132-142, Dol:10.1109/ TITS.2003.821294.

[6] Shen, W.X., Chan, C.C., Lo, E.W.C., Chau, K.T. (2002). Adaptive neuro-fuzzy modeling of battery residual capacity for electric vehicles. IEEE Transactions on Industrial Electronics, vol. 49, no. 3, p. 677-684, DOI:10.1109/TIE.2002.1005395.

[7] Chau, K.T., Wu, K.C., Chan, C.C. (2004). A new battery capacity indicator for lithium-ion battery powered electric vehicles using adaptive neuro-fuzzy inference system. Energy Conversion and Management, vol. 45, no. 11-12, p. 1681-1692, DOl:10.1016/j. enconman.2003.09.031.

[8] Niasar, A.H., Moghbeli, H., Kazemi, R. (2003). Yaw moment control via emotional Adaptive Neuro-Fuzzy Controller for independent rear wheel drives of an electric vehicle. Proceedings of 2003 IEEE Conference on Control Applications, vol. 1, p. 380-385.

[9] Kadir, Z.A., Hudha, K., Ahmad, F., Abdullah, M.F., Norwazan, A.R., Mohd Fazli, M.Y., Khalid, A.J., Gunasilan, M. (2012). Verification of 14DOF full vehicle model based on steering wheel input. Applied Mechanics and Materials, vol. 165, p. 109-113, D0I:10.4028/www.scientific.net/AMM. 165.109.

[10] Harun, M.H., Abdullah,W., Jamaluddin, H., Rahman, R.A. Hudha, K. (2014). Hybrid skyhook-stability augmentation system for ride quality improvement of railway vehicle. Applied Mechanics and Materials, vol. 663, p. 141-145, D0I:10.4028/ www.scientific.net/ AMM.663.141.

[11] Crews, J.H., Mattson, M.G., Buckner, G.D. (2011). Multiobjective control optimization for semi-active vehicle suspensions. Journal of Sound and Vibration, vol. 330, no. 23, p. 5502-5516, DOl:10.1016/j.jsv.2011.05.036. 